\title{
The bleeding mother and her baby: a study to determine the fetomaternal outcome in cases of placenta previa
}

\author{
Preeti Frank Lewis, Sana Tarannum Bijapur*, Deepika Gurnani
}

Department of Obstetrics and Gynecology, Sir JJ Hospital and Grant Medical College, Mumbai, Maharashtra, India

Received: 01 July 2020

Revised: 08 August 2020

Accepted: 14 August 2020

\section{*Correspondence:}

Dr. Sana Tarannum Bijapur,

E-mail: bijapursana@yahoo.in

Copyright: (c) the author(s), publisher and licensee Medip Academy. This is an open-access article distributed under the terms of the Creative Commons Attribution Non-Commercial License, which permits unrestricted non-commercial use, distribution, and reproduction in any medium, provided the original work is properly cited.

\begin{abstract}
Background: Placenta previa is one of the major causes for obstetric hemorrhagic morbidity and mortality with increasing incidence in recent times. This study aims at determining risk factors, maternal and fetal outcome associated with placenta previa.

Methods: This was an observational, retrospective study conducted at a tertiary care hospital in Mumbai from May 2017 to March 2020. A total of 102 women with placenta previa during the study period were included, their case records critically analyzed to identify risk factors, maternal outcome in relation with blood transfusion required, ICU admission, obstetric hysterectomy and fetal outcome pertaining to prematurity, asphyxia and mortality.

Results: A total of 102 patients were analyzed. Placenta previa was more common in $>26$ years of age, multipara $(64.7 \%)$, with previous history of caesarean sections $(21.5 \%)$ and previous curettage (11.7\%), $44.2 \%$ babies born were preterm, $4.4 \%$ stillbirths and $8.5 \%$ neonatal deaths. Maternal complications like antepartum hemorrhage was seen in $58.8 \%$ patients and postpartum hemorrhage in $33.3 \%$, blood transfusion was required in only 18 patients post operatively, bladder rent was seen in 3 patients and there was no maternal mortality. 44 patients required uterine artery ligation, Ashok Anand stitch was taken in 37 patients, uterus compression sutures in 10, obstetric hysterectomy in 7 patients and internal iliac artery ligation in 2 patients.

Conclusions: Early identification of women at risk, obstetric preparedness and simple techniques like uterine artery ligation, Ashok Anand stitch and uterine compression sutures can help in effectively reducing need for multiple blood transfusions and morbidity.
\end{abstract}

Keywords: Antepartum hemorrhage, Ashok Anand stitch, Obstetric hemorrhage, Placenta previa

\section{INTRODUCTION}

Child birth is like a new life for the mother. Pregnancy and parturition can be associated with many life endangering complications, that having a healthy mother and a healthy baby is a bliss. Obstetric hemorrhage is a major cause for maternal mortality and morbidity in the world with placenta previa being an independent risk factor for maternal haemorrhagic morbidity. ${ }^{1}$

Placenta previa is defined as an obstetric complication characterized by placental implantation into the lower segment of the uterine wall, covering part of or the entire cervix. It was originally described using transabdominal scan and graded according to the relationship and/or the distance between the lower placental edge and the internal os of the uterine cervix. ${ }^{2}$

Type I or minor previa is lower edge of placenta inside the lower uterine segment; type II or marginal previa as a lower edge reaching the internal os; type III or partial previa when the placenta partially covers the cervix; and type IV or complete previa when the placenta completely covers the cervix. ${ }^{2}$ 
Recently, American Institute of Ultrasound in Medicine (AIUM) has suggested that the term true placenta previa be used when the placenta lies directly over the internal os and for pregnancies greater than 16 weeks of gestation, the placenta should be reported as 'low lying' when the placental edge is less than $20 \mathrm{~mm}$ from the internal os, and as normal when the placental edge is $20 \mathrm{~mm}$ or more from the internal os on TVS or $\mathrm{TAS}^{3}$ This new classification could better define the risks of perinatal complications, such as antepartum haemorrhage and major postpartum haemorrhage $(\mathrm{PPH})$, and has the potential of improving the obstetric management of placenta previa. ${ }^{4}$

The rates of placenta previa and accreta have increased as a result of rising rates of caesarean deliveries, increased maternal age and use of assisted reproductive technology (ART), straining the maternity-related resources. ${ }^{2}$ Placenta previa has also been linked to maternal complications like emergency hysterectomies, multiple blood transfusions, urogenital injuries, sepsis, intensive care unit (ICU) and prolonged hospital stay as well as adverse fetal outcomes such as prematurity, low birth weight, congenital abnormalities, stillbirth, and early neonatal death. ${ }^{5}$

The aim of this study to determine the obstetric risk factors, maternal complications, mortality and perinatal outcome in women presenting with placenta previa and aid in better management and prevention of adverse fetomaternal outcome in these women.

\section{METHODS}

This was a retrospective, observational study conducted at a tertiary care hospital in Mumbai for a period of 3 years, from April 2017 to March 2020. A total of 102 women with ultrasonography suggestive of placenta previa were included and those with placental abruption or other antepartum hemorrhage causes excluded. Case records were critically analysed to identify risk factors, type of placenta previa, maternal outcome in relation to mode of delivery, blood transfusion required, ICU admission, additional surgical procedures required, obstetric hysterectomy, sepsis, wound gapes and fetal outcome with fetal weight, prematurity, congenital anomalies, asphyxia and mortality.

\section{RESULTS}

In this study, maximum cases $(33.3 \%)$ with placenta previa were seen in age group 26-30 years, followed by $28.4 \%$ in age group 31-35 years. $28 \%$ cases were registered.

Placenta previa was more common in women $>3$ gravida (49), multipara $(64.7 \%)$ and with previous history of caesarean section (21.5\%), abortion (12.3\%) and curettage $(11.7 \%)$.
In this study, most common type of placenta was complete placenta previa (42\%). Placenta accreta was found in $7.8 \%$ patients. According to AIUM classification, $79.3 \%$ had true placenta previa.

Table 1: Incidence of placenta previa according to maternal age.

\begin{tabular}{|lll|}
\hline Age (in years) & Number of cases & Percentage \\
\hline $\mathbf{2 1 - 2 5}$ & 22 & 21.5 \\
\hline $\mathbf{2 6 - 3 0}$ & 34 & 33.3 \\
\hline $\mathbf{3 1 - 3 5}$ & 29 & 28.4 \\
\hline$>\mathbf{3 5}$ & 17 & 16.6 \\
\hline Total & 102 & 100 \\
\hline
\end{tabular}

Table 2: Correlation with risk factors.

\begin{tabular}{|ll|}
\hline Risk factors & Number of cases \\
\hline Gravida & \\
\hline Gravida 1 & 28 \\
\hline Gravida 2 & 23 \\
\hline > Gravida 3 & 49 \\
\hline Parity & \\
\hline Nulliparous & 36 \\
\hline Para1 & 27 \\
\hline Para 2 & 35 \\
\hline Para 3 & 4 \\
\hline Previous LSCS & 22 \\
\hline Previous abortions & 13 \\
\hline Previous check curettage & 12 \\
\hline Infertility & 4 \\
\hline Twins & 3 \\
\hline
\end{tabular}

Table 3: Classification according placental localisation.

\begin{tabular}{|lll|}
\hline Placenta type & Number of cases & Percentage \\
\hline Type 1 & 3 & 2.9 \\
\hline Type 2 & 18 & 17.6 \\
\hline Type 3 & 38 & 37.2 \\
\hline Type 4 & 43 & 42.1 \\
\hline
\end{tabular}

A total $93 \%$ delivered by caesarean section and $7 \%$ who had placenta $>2 \mathrm{~cm}$ away from the internal os, delivered vaginally.

A total $42.9 \%$ babies were preterm with $8.2 \%$ born before 28 weeks. A total $16.1 \%$ babies born were $<1.5 \mathrm{~kg}$ and $33.3 \%$ of $2.5-3.5 \mathrm{~kg}$.

There were 52 males, 53 females, 8 babies with malpresentation ( 5 breech and 3 transverse lie) and 2 babies had congenital anomalies.

There were 5 still births and 9 neonatal deaths between day 2 and 8.32 babies were admitted to NICU especially for low birth weight in 25 and respiratory distress in 12 . 
Table 4: Neonatal outcome.

\begin{tabular}{|lll|}
\hline Neonatal outcome & \multicolumn{1}{c|}{$\begin{array}{l}\text { Number of } \\
\text { babies }\end{array}$} & Percentage \\
\hline Gestational age (in weeks) & \\
\hline$<28$ & 9 & 8.5 \\
\hline $29-32$ & 13 & 12.3 \\
\hline $33-36$ & 23 & 21.9 \\
\hline$>37$ & 60 & 57.1 \\
\hline Birth weight & & \\
\hline$<1.5$ & 17 & 16.1 \\
\hline $1.6-2$ & 12 & 11.4 \\
\hline $2-2.5$ & 41 & 39.0 \\
\hline $2.5-3.5$ & 35 & 33.3 \\
\hline Gender & & \\
\hline Male & 52 & 49.5 \\
\hline Female & 53 & 50.6 \\
\hline Congenital anomalies & 2 & 1.7 \\
\hline Asphyxia & 25 & 24.0 \\
\hline Still birth & FSB-4 & 3.6 \\
\hline NND & MSB-1 & 0.8 \\
\hline NICU admission & 9 (day 2-8) & 8.5 \\
\hline & 32 & 30.4 \\
\hline & & \\
\hline & & \\
\hline
\end{tabular}

Table 5: Surgical management.

\begin{tabular}{|ll|}
\hline Surgical management & Number of cases \\
\hline Uterine artery ligation & 44 \\
\hline ARA stitch & 37 \\
\hline B lynch & 10 \\
\hline Obstetric hysterectomy & 7 \\
\hline Internal iliac artery ligation & 2 \\
\hline
\end{tabular}

Table 6: Maternal complications associated with placenta previa.

\begin{tabular}{|lll|}
\hline Maternal complications & $\begin{array}{l}\text { Number } \\
\text { of cases }\end{array}$ & Percentage \\
\hline Antepartum hemorrhage & 60 & 58.8 \\
\hline Blood transfusion & Intra op-34 & 32.3 \\
\cline { 2 - 3 } & Post op-18 & 17.1 \\
\hline FFP transfusion & 9 & 8.5 \\
\hline Postpartum hemorrhage & 34 & 33.3 \\
\hline Post op hb <9 gm\% & 48 & 47 \\
\hline Shock & 1 & 0.9 \\
\hline Bladder rent & 3 & 2.9 \\
\hline Icu admission & 6 & 5.8 \\
\hline $\begin{array}{l}\text { Prolonged hospital stays } \\
\text { (>5 days) }\end{array}$ & 27 & 26.4 \\
\hline Wound gape & 11 & 10.7 \\
\hline Sepsis & 1 & 0.9 \\
\hline
\end{tabular}

A total $44 \%$ patients required uterine artery ligation, Ashok Anand stitch was taken in 37 patients, uterus compression sutures in 10 , obstetric hysterectomy in 7 patients and internal iliac artery ligation in 2 patients.
In the present study, placenta previa was associated with antepartum hemorrhage in $58.8 \%$ patients and postpartum hemorrhage in $33.3 \%$, blood transfusion was required in 34 patients intra operatively and in 18 patients post operatively. FFP transfusion was required in 9 patients. Post-operative hemoglobin was $<9$ in 48 patients, a bladder rent was seen in 3 patients, 6 patients required ICU admission, 27 patients had prolonged hospital stay $>5$ days. 11 patients had wound gape and 1 had sepsis. There was no maternal mortality.

\section{DISCUSSION}

Placenta previa is one of the most dreadful obstetric complications because of its association with high maternal and neonatal mortality and morbidity. Early recognition of women with risk factors, timely diagnosis and intervention can help improve management of these women.

Increasing age and multiparity are important risk factors for development of placenta previa. In this study $45 \%$ women were more than 30 years of age out of which $15 \%$ were more than 35 years in comparison around 1/4th patients were more than 30 years old in study done by Sarojini et al. ${ }^{6}$

An association could be made with increasing number of pregnancies as $72 \%$ patients were multigravida, with $39 \%$ having $>2$ gravidity consistent with findings reported by Hafeez et al with $92 \%$ multigravida and $38 \%>3$ parity and Rangaswamy et al with $76 \%$ multigravida and $42 \%$ of $>2$ gravidity. ${ }^{7,8}$

The increased risk of placenta previa among multigravida women may be explained by degenerative change to the uterine vasculature, leading to under perfusion of the placenta and hence compensatory enlargement leading to increased likelihood of implantation on the lower segment. ${ }^{9}$

Previous history of caesarean section is a key risk factor with $48.64 \%$ in study by Hafeez et al, $36.7 \%$ by Sarojini et al and $21.5 \%$ in the present study had a history of previous caesarean section. ${ }^{6,7} 11.7 \%$ had history of abortion followed by curettage in this study. Other factors increasing risk of placenta previa like infertility treatment, found in 4 patients and twin gestation found in 3 patients in this study were comparable to findings in similar studies. ${ }^{10,11}$

In this study the placenta was low lying in $17.6 \%$ patients, true placenta previa in $79.3 \%$ and placenta accreta was found in 8 patients similar to findings of Sarojini et al with $60.4 \%$ having major placenta previa. ${ }^{6}$

A total $93 \%$ cases underwent cesarean delivery, main indication being major degree placenta previa and results are comparable to the study conducted by Sarojini et al where $85.8 \%$ underwent caesarean section. ${ }^{6}$ 
In this study, $42.9 \%$ babies were preterm with $8.2 \%$ born before 28 weeks mainly due to antepartum hemorrhage. $1.7 \%$ babies had congenital anomalies. $30.4 \%$ had NICU admissions largely for low birth weight followed by respiratory distress. The results were consistent with findings of Sarojini et al and Hafeez et al. ${ }^{6,7}$

A total $67 \%$ were of low birth weight (birth weight $<2.5$ $\mathrm{kg}$ ) out of which $16.1 \%$ were $<1.5 \mathrm{~kg}$, little more than that reported by other studies. ${ }^{6-8}$

Malpresentations were present in $7.4 \%$ (5 breech and 3 transverse lie), lesser than found in study by Rangaswamy (40\%). ${ }^{8}$ In a study by Senkoro, 12 fetal malpresentation had 3-fold higher odds of having placenta previa as compared to those with normal fetal presentation. The association between placenta previa and fetal malpresentation may be explained by the fact that the placenta in the lower segment obstructs the engagement of the head; this may cause the transverse or breech lie in the womb.

Looking at the perinatal mortality, there were around $4.4 \%$ stillbirths with 4 fresh still births and 1 macerated still birth and $8.5 \%$ neonatal deaths between days 2 and 8 lesser than found by Rangaswamy et al. ${ }^{8}$

Placenta previa has nine times increased risk of antepartum, threefold higher odds of blood transfusion and fivefold higher odds of prolonged hospital stay (Senkoro). ${ }^{12}$ In this study, placenta previa presented with antepartum hemorrhage in $58.8 \%$ patients.

Uterine artery ligation was done in 44 patients. Ashok Anand's stitch is a simple and effective technique followed in authors study institution to control lower uterine segment blood loss in placenta previa. ${ }^{13}$ A stitch is taken bilaterally above the lateral fornices and just below the uterine angles, occluding the collaterals supplying the lower segment. As these are end arteries, their occlusion leads to apparent devascularization of the lower segment, thus helping in control of postpartum hemorrhage. In this study, Ashok Anand stitch was performed in 37 patients and uterus compression sutures taken in 10 patients. Obstetric hysterectomy was needed in only 7 patients which had morbidly adherent placenta and internal iliac artery ligation in 2 patients, which was similar or lower than other similar studies. ${ }^{6,7}$

The increased risk of postpartum hemorrhage in women with placenta previa is well known necessitating blood transfusion. Therefore, it is important that blood transfusions and the obstetric emergency care be readily available at any facility treating women with placenta previa.

Only 34 patients intra operatively and 18 post operatively required blood transfusion. FFP transfusion was required in 9 patients. The need for blood and blood products was significantly less in this study compared to studies by
Rangaswamy et al and Hafeez et al, where all patients with placenta previa received blood transfusions and $83 \%$ in study by Sarojini et al. ${ }^{6-8}$ Prompt use of uterotonics and conservative uterine surgeries avoided need for blood transfusion.

Maternal complications like bladder rent was seen in 3 patients, 27 patients had prolonged hospital stay $>5$ days, 11 had wound gape and 1 sepsis. These findings were comparable to findings of Hafeez et al and Sarojini et al. ${ }^{7,8}$ In this study only 7 patients required ICU admission which was significantly less than that seen in study by Sarojini et al $(86.8 \%) .{ }^{6}$ There was no maternal mortality.

\section{CONCLUSION}

Placenta previa is one of the main causes for maternal and perinatal morbidity and mortality leading to antepartum haemorrhage, postpartum hemorrhage, increased operative interference, increased blood transfusion requirement, wound gape, perinatal birth asphyxia, morbidity and mortality. Early identification of women at risk, obstetric preparedness and simple techniques like uterine artery ligation, Ashok Anand stitch and uterine compression sutures can help in effectively reducing need for multiple blood transfusions and morbidity.

Funding: No funding sources

Conflict of interest: None declared

Ethical approval: The study was approved by the Institutional Ethics Committee

\section{REFERENCES}

1. Gibbins KJ, Einerson BD, Varner MW, Silver RM. Placenta previa and maternal hemorrhagic morbidity. J Matern Fetal Neonatal Med. 2018;31(4):494-9.

2. Jauniaux E, Alfirevic Z, Bhide AG, Belfort MA, Burton GJ, Collins SL, et al. Royal College of Obstetricians and Gynaecologists: placenta praevia and placenta accreta: diagnosis and management: green-top guideline no. 27a. BJOG. 2019;126(1):e1e48.

3. Reddy UM, Abuhamad AZ, Levine D, Saade GR. Fetal imaging workshop invited participants. Fetal imaging: executive summary of a joint Eunice Kennedy Shriver National Institute of Child Health and Human Development, Society for Maternal-Fetal Medicine, American Institute of Ultrasound in Medicine, American College of Obstetricians and Gynecologists, American College of radiology, society for pediatric radiology, and society of radiologists in ultrasound fetal imaging workshop. J Ultrasound Med. 2014;33:745-57.

4. Vahanian SA, Lavery JA, Ananth CV, Vintzileos A. Placental implantation abnormalities and risk of preterm delivery: a systematic review and metaanalysis. Am J Obstet Gynecol. 2015;213:S7890 . 
5. Archibong, Eric Ahmed, El. Risk factors, maternal and neonatal outcome in major placenta previa: a prospective study. Ann Saudi Med. 2001;21:245-7.

6. Sarojini MK. Radhika. Clinical study of placenta previa and its effect on maternal health and fetal outcome. Int $\mathbf{J}$ Reprod Contracept Obstet Gynecol. 2016;5:3496-9.

7. Hafeez M, Badar N, Akram N. Placenta previa, prevalence, risk factors and outcome. JIMSA. 2014;8(1):208-11.

8. Rangaswamy M, Govindaraju K. Fetomaternal outcome in placenta previa - a retrospective study in teaching hospital. Int J Reprod Contracept Obstet Gynecol. 2016;5:3081-4.

9. Kiondo P, Wandabwa J, Doyle P. Risk factors for placenta previa presenting with severe vaginal bleeding in Mulago hospital, Kampala, Uganda. African Health Sci. 2008;8(1):44-9.

10. Romundstad LB, Romundstad PR, Sunde A, von Düring V, Skjærven R, Vatten LJ. Increased risk of placenta previa in pregnancies following IVF/ICSI; a comparison of ART and non-ART pregnancies in the same mother. Human Reprod. 2006;21(9):2353-8.
11. Kohari KS, Roman AS, Fox NS, Feinberg J, Saltzman DH, Klauser CK, et al. Persistence of placenta previa in twin gestations based on gestational age at sonographic detection. J Ultrasound Med. 2012;31(7):985-9.

12. Senkoro E, Mwanamsangu AH, Chuwa FS, Msuya SE, Mnali OP, Brown BG, et al. Frequency, risk factors, and adverse fetomaternal outcomes of placenta previa in Northern Tanzania. J Pregnancy. 2017;2017:7.

13. Anand AR, Gupta D, Prasad A. Reducing intraoperative lower segment blood loss in placenta previa with Ashok Anand stitch. I Int J Reprod Contracept Obstet Gynecol. 2013;2(2):135-40.

Cite this article as: Lewis PF, Bijapur ST, Gurnani D. The bleeding mother and her baby: a study to determine the fetomaternal outcome in cases of placenta previa. Int J Reprod Contracept Obstet Gynecol 2020;9:3775-9. 